\title{
A Hybrid Approach for Recognition of Hand Written Devnagri Compound Characters
}

\author{
Prashant Yawalkar ${ }^{1}$ and M. U. Kharat ${ }^{2}$ \\ ${ }^{1}$ Research Scholar, ${ }^{2}$ Professor and Head \\ ${ }^{1 \& 2}$ Department of Computer Engineering, MET's Institute of Engineering, Bhujbal Knowledge City, Maharashtra, India \\ E-Mail: prashant25yawalkar@gmail.com, mukharat@rediffmail.com
}

\begin{abstract}
Being an effective tool in the world of communication, numerous techniques have been developed for documenting the handwritten text. Few of the exceptional techniques describe the environment of handwritten scripts and further convert it into electronic data by implementing various algorithms. Devnagri is one of the widely used scripts for most popular and commonly used languages like Marathi and Hindi. Recent development in the field of handwritten character recognition based on different methodologies like neural network, fuzzy logic, and deep neural networks has shown remarkable improvement in character recognition accuracy from $75 \%$ to $96 \%$. We propose a fuzzy-Neural hybrid approach for recognition of hand written Devnagri compound character that uses a rotation invariant rule-based thinning algorithm as one of the major pre-processing activity. Thinning the characters to their central line, preserving the shape of the character are the distinctive features of thinning algorithm. Concurrent application of different rules to each pixel of the character image results into symmetrical thinning as well as improves the overall speed of the system. The system is trained using Neural Network where the weights are optimized using fuzzy rules improving the accuracy of the system. Results obtained for the fuzzy-neural based system with thinning helps in preserving the topology of the characters written in Devnagri and prove that accuracy of the system has stabilized in the band of $92-97 \%$ which was fluctuating in the band of $89-94 \%$ for the previously implemented systems. The system also shows a substantial improvement in accuracy for recognition of compound characters in comparison with our previously implemented system.
\end{abstract}

Keywords: Character Recognition, Neural Network, Rotation Invariant, Thinning, Fuzzy Logic, Fuzzy-Neural, Image Acquisition, Segmentation, Feature Extraction

\section{INTRODUCTION}

Recognition of handwritten characters is a difficult task for machines while the same task is carried out accurately when given to the humans. Devnagri is one of the widely used scripts for most popular and commonly used languages like Marathi and Hindi. Optical Character recognition (OCR) for Devnagri script becomes specifically complex due to complicated curves and various shapes present in these languages [1]. Optical character recognition is nothing but electronic translation of scan images of handwritten, typewritten or printed wording interested in system-encoded content [2]. This process can be used for converting books and documents into electronics form, managing a recordkeeping system in an office, or publishing the text on a website. Using OCR we can also modify the text, search for a phrase, store it efficiently, display a replica free of scanning artifacts, as well as use processes like machine translation, text-to-speech and text mining to it.

A. Fundamental Stages in Character Recognition: Many times differentiating the hand written characters is almost impossible even to the human eye, and that they can only be distinguished by context for some hand-writing. It becomes critical to identify the minute differences between them in order to distinguish such characters. An important issue of different relative proportions while writing the character by different writers needs to be considered, while dealing with handwritten characters. Even the same person may not always write the same letter with the same proportions [3]. The fundamental stages in hand written character recognition system like acquiring the image, applying the pre-processing activities, decomposing in to segments, extracting the features, and finally classification and recognition. The process of scanning and translating a paper document in to digital form is called image acquisition. Almazan et al., addressed the issues related to word spotting and word identification of images [4].

While capturing the image depending on the quality of the scanner noise may be introduced. Preprocessing focuses on deduction of such noise. Few more activities like thinning, normalization and segmentation of image needs to be carried out for improving the process of recognition [5]. Normalization involves resizing of characters for stroke width, slant, slope, height of the characters. Further trimming down each character image to vertical letters of uniform height made up of one pixel-wide stroke is carried out. A Normalization free, flexible and size invariant system that recognizes handwritten Devnagri characters was presented by Mukerji and Rege. Separation of characters in its constituent strokes by modification in thinning technique and direction codes worked efficiently and improved the overall accuracy of the system [6]. A 8-step Rotation invariant thinning algorithm constructing 20 rules that are concurrently applied to each pixel iteratively, in order to remove every point lying on the exterior boundaries of the symbol was developed that helped in preserving the shape of the character as well as improving the recognition accuracy [7].

Segmentation which is a decisive activity in the process of character recognition decomposes the input image into sub 
images by means of separating lines and words. Different techniques for decomposition of multiple touching handwritten Devnagri characters were presented [8]. Extracting features from the input image in the sense of information that must be similar for similar images and distinct for other images. Selection of feature extraction technique becomes a key aspect in achieving high recognition performance since these features play major role in pattern recognition. Some of the feature extraction methods like projection, bordered transition, zoning etc are carried out [9]. In projection method, data is compressed by means of projection where in marginal distributions are generated through counts of black pixels taken along parallel lines of the image. Kekre et al., implemented the Half toning technique for image compression and showed that it gives best compression factor $12.5 \%$ at the source [10]. Assuming vertical orientation of each letter into four quadrants of equal size is the key feature in Border translation technique. Zoning involves dividing the character into minor pieces of area. In the process of Classification features of the image are used as the basis for assigning data to their equivalent groups with respect to groups having similar features. Thus decision rules are used for dividing the feature space into several classes. Various classification methods like support vector machine, Genetic Algorithms, Fuzzy Logic, neural network etc are used for recognition of handwritten character.

\section{RELATED WORK}

A writer independent system that works in four phases for recogni tion of handwritten sentences was presented by Beatrice Lazzerini et al.,. The different phases included preprocessing the input in order to split each sentence in to words, combination of neural network and fuzzy logic technique for recognition of every individual character, lexical and grammatical analysis of the recognized text, and finally combining these recognized characters to recognize the words and later sentence [11]. A robust and accurate system based on a innovative approach for extracting the feature in terms of normalized vector having distance and angle from a fixed point for each block that is obtained as a result of partitioning the image in to blocks was presented by $\mathrm{M}$ Hanmandlu et al. Extra barbs introduced due to thinning technique applied may drop in to incorrect box distorting the shape of the character and further resulting into incorrect classification of the character. A proper thinning technique with no extra barbs and smoothness in characters shape can certainly improve the recognition rate. This system is Language independent, font and size independent as well as insensitive to non connected characters at any stage [12].

A method for automatic construction of implied fonts from handwritten data by adding extra information to character outlines in the form of essential restrictions in order to overcome adverse effects of the rasterization process was described. A dynamic strategy that uses global as well as local features to find correspondence between an input character and a stored template inspite of its difference in shape and topology was implemented [13]. In order to deal with MICR code lying at the bottom of bank cheque or in some security documents, a fuzzy system that classifies the characters using cross correlation between the extracted features was proposed. The system is efficient enough to handle deformation of characters due to thresholding and skewing [14]. Recognition of Arabic characters based on fuzzy features like height-to-width ratio, number of pixels, length, and width was introduced by Zeki Khedher and Ghayda Al-Tali. Fuzzy rules based on Membership functions derived from handwritten data were used for fuzzy logic treatment [15]. A technique to deal with the difficulty in restoring the order of writing from a graph representation of an image of single-stroked handwriting was introduced. Further a framework based on exploring interior structure of the graph was presented to determine the relation of edge continuity at even degree nodes [16]. For a high-level representation of graphical symbols effectively and efficiently, an hierarchical method was introduced that was used for recognition of hand written shapes [17]. A powerful approach that partitions the problem space into sub-problems and extracts generic features to build a feature vector for constructing Local Linear Models (LLMs) and later Local Linear Neuro Fuzzy (LLNF) Model was used for classification and recognition of hand written characters by Daryoush et al., [18].

A effective method for recognition of handwritten devnagri compound character based on combination of different features and neural network was introduced. Pre-classifying the characters into different classes based on structural features, further extracting features like wavelet approximation and modified wavelet in order to train the neural network constructed for each structural class. Use of LM training algorithm helps in reducing the training time, while use of modified wavelet method substantially increases the range of signal and helps in genereting unique feature for every character thereby improving the accuracy of recognition [19]. An hybrid approach with combination of back propogation neural network and weight optimization using genetic algorithm was introduced for recognizing uppercase English characters [20]. Fusion of different statistical feature extraction techniques like: Run Length Matrix, Moment Invariants, Intensity Histogram, Gray Level Co-occurrence Matrix to develop a new hybrid method that improved the recognition accuracy for Arabic characters [21]. A hand written postal address recognition system based on elliptical beta was presented for Arabic language [22]. A standard deviation \& and zone centric based feature extraction method for better accuracy while training and testing the Neural Network combined with Genetic Algorithm for recognition of Odia handwritten character was presented [23]. An efficient Hybrid approach that combines Particle Swarm Optimization and Back propagation algorithm for enhancing the classification performance of Hand Writing Recognition by means of optimizing ANN weights was presented [24]. A recognition system that normalizes the input image to $30 \mathrm{X} 30$ size and then extracts features in the form of orthogonal moment for 
recognizing hand written compound characters in Devnagri was presented [25]. A hybrid approach to detect and recognize texts in CAPTCHA images was introduced which helped in checking the strength of CAPTCHA [26]. A grid based method that divides the character image into $n$ grids or zones of equal size and computes the average distance of each pixel present in the grid was developed. It further combines the image and zone centroids to obtain a feature vector which is given as an input to the feed forward neural network for the purpose of recognition[27]. To recognize isolated characters in Gujrati each feature was defined with a membership function and was combined with t-norms to optimized the weights of back propogation neural network that helped in improving the recogintion accuracy [28]. Inorder to improve the recognition accuracy of Devnagri script, a framework that combined neural network and feature codebook was implemented [29]. Combining the adaptive capabilities of neural network with qualitative approach in fuzzy logic the ANFIS model was developed and further analysed to obtain the conclusions concerning the saliency of features on classification [30]. Jangid and Srivastava trained the deep convolution neural network layer wise and used an adaptive gradient technique that gave an recognition accuracy of $96 \%$ [31].

\section{PROPOSED SYSTEM}

Different methods used for classification have their own strengths and weaknesses. This makes it necessary to combine multiple classifiers which helps in solving the problem of classification in effective manner. Training multiple classifiers on the same data may result in to different performances at global as well as local level. Different classifiers may have its best performing region in the feature space which may be the reason for its superiority. Few classifiers like neural networks have inherent randomness which is useful while training the network. Thus instead of considering the best network and rejecting the others, combining different networks in order to take maximum benefits of learning from the data can result in to effective classification. We have proposed the combination of Fuzzy with Neural Network (Fuzzy Neural approach) whose diagrammatic representation is shown in Fig. 1. Initially the scanned handwritten document for devnagiri is subjected to pre-processing, which comprises of phases like Edge detection, binarization, denoising, and thinning.

An 8 step Rotation in-variant thinning algorithm constructing 20 rules that are concurrently applied to each pixel iteratively, in order to remove every point lying on the exterior boundaries of the symbol. This process is continued for all the regions of the symbol having width greater than one pixel until there are no further changes. If the Pixel has width equal to one pixel measured in any direction then it is not removed since it belongs to symbols central line in the resultant graph.Further features are extracted from the preprocessed image and the neural network is trained accordingly.

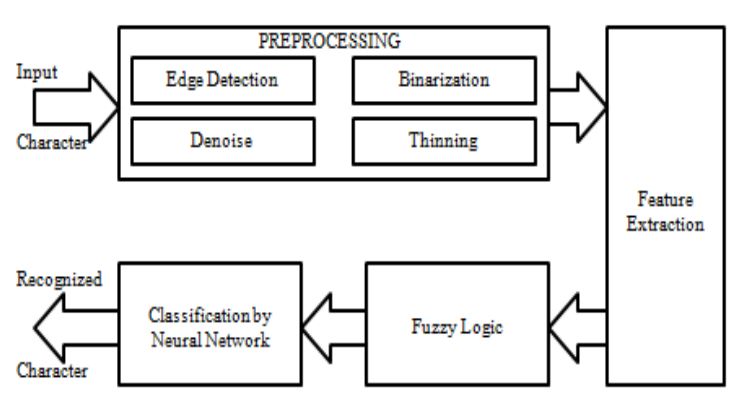

Fig. 1 Architecture of the proposed fuzzy neural system

Subsequently, the classification process is done using NN where the new training algorithm is used, in which the weights are optimized using fuzzy rules given as If $\left(\left(\mathbf{C}_{\mathbf{2 1}}==\right.\right.$ Average $\|$ Average-High $\|$ High $) \|\left(C_{22}\right.$ is Average $\|$ Average-High $\|$ High)) then $\mathrm{C}_{\mathbf{2 1}}=0.4$.

Else

If $\left(\left(\mathrm{C}_{13}\right.\right.$ is Low $\|$ Low- Average $\|$ Average $) \|\left(\mathrm{C}_{13}\right.$ is Low $\|$ Low- Average $\|$ Average)) then $\mathrm{C}_{13}=0.4$.

Optimizing the weights using fuzzy rules improvises the classification efficiency ultimately improving the recognition accuracy. The classification output is in the form of recognized character.

\section{RESULTS AND DISCUSSION}

The implemented system is trained using standard Devnagri Handwritten Character Dataset (DCD) consisting of more than 12000 images; 185 each of 36 consonants, 211 each of 12 Vowels, and 288 each of 10 digits. We have created a test dataset of more than 1650 images; 35 each of 36 consonants and 35 each of 12 Vowels has been used for testing the implemented system. We have also created dataset for compound characters consisting of 20 compound characters with 35 images of each. The recognition system has been implemented using combined approach of Neural Network and fuzzy logic with thinning as a major preprocessing activity. The implemented system when tested on the trained data gave $91-94 \%$ accuracy without thinning and more than $97 \%$ with thinning. Further when tested for test data the accuracy was $85-91 \%$ without thinning and 88-95\% with thinning (Table I and Fig. 4). Our previously implemented systems Neural based and Fuzzy based have the accuracy in the range of $86.4 \%$ to $96 \%$ as shown in the comparitive graph. Thus the system performs considerably well compared to the previously implemented systems as well as our previously implemented approach of neural network by stabilizing the accuracy in between 91$94 \%$ compared to the previous results of $75-96 \%$ (Table III and Fig. 5). The system has also been trained and tested for hand written compound characters in Devnagri which gave an accuracy of around 85-91\% (Table II and Fig. 2) during the recognition which is much better than our previous neural network based system that gave accuracy of $45-55 \%$ and Fuzzy based system that gave accuracy of $80-83 \%$ as shown in Fig 3. Comparison with the previously implemented system shows that the proposed system performs better by showing a considereble improvement of $2-3 \%$ in the recognition accuracy. 
TABLE I RESUlts OBTAINED For FuZZY NEURAL BASED SYSTEM With AND Without THINNING

\begin{tabular}{|c|c|c|c|c|c|c|c|c|c|}
\hline \multirow{2}{*}{$\begin{array}{c}\text { Input } \\
\text { Character }\end{array}$} & \multicolumn{2}{|c|}{ Recognition out of 35} & \multirow{2}{*}{$\begin{array}{c}\text { Accuracy } \\
\text { Without } \\
\text { Thinning }\end{array}$} & \multirow{2}{*}{$\begin{array}{c}\text { Accuracy } \\
\text { With } \\
\text { Thinning }\end{array}$} & \multirow{2}{*}{$\begin{array}{c}\text { Input } \\
\text { Character }\end{array}$} & \multicolumn{2}{|c|}{ Recognition out of 35} & \multirow{2}{*}{$\begin{array}{l}\text { Accuracy } \\
\text { Without } \\
\text { Thinning }\end{array}$} & \multirow{2}{*}{$\begin{array}{c}\text { Accuracy } \\
\text { With } \\
\text { Thinning }\end{array}$} \\
\hline & $\begin{array}{l}\text { Without } \\
\text { Thinning }\end{array}$ & $\begin{array}{c}\text { With } \\
\text { Thinning }\end{array}$ & & & & $\begin{array}{c}\text { Without } \\
\text { Thinning }\end{array}$ & $\begin{array}{c}\text { With } \\
\text { Thinning }\end{array}$ & & \\
\hline अ & 32 & 33 & 91.42 & 94.28 & ढ & 33 & 33 & 94.28 & 94.28 \\
\hline आ & 32 & 33 & 91.42 & 94.28 & ण & 33 & 34 & 94.28 & 97.14 \\
\hline इ & 32 & 33 & 91.42 & 94.28 & त & 33 & 34 & 94.28 & 97.14 \\
\hline ई & 32 & 33 & 91.42 & 94.28 & थ & 33 & 34 & 94.28 & 97.14 \\
\hline 3 & 32 & 34 & 91.42 & 97.14 & द & 32 & 34 & 91.42 & 97.14 \\
\hline ऊ & 32 & 34 & 91.42 & 97.14 & ध & 32 & 32 & 91.42 & 91.42 \\
\hline ए & 33 & 34 & 94.28 & 97.14 & न & 33 & 33 & 94.28 & 94.28 \\
\hline ऐ & 33 & 34 & 94.28 & 97.14 & प & 32 & 33 & 91.42 & 94.28 \\
\hline ओ & 33 & 34 & 94.28 & 97.14 & फ & 33 & 34 & 94.28 & 97.14 \\
\hline औ & 32 & 33 & 91.42 & 94.28 & ब & 32 & 33 & 91.42 & 94.28 \\
\hline अं & 32 & 33 & 91.42 & 94.28 & भ & 32 & 33 & 91.42 & 94.28 \\
\hline अ: & 33 & 34 & 94.28 & 97.14 & म & 33 & 33 & 94.28 & 94.28 \\
\hline क & 33 & 34 & 94.28 & 97.14 & य & 33 & 34 & 94.28 & 97.14 \\
\hline ख & 33 & 34 & 94.28 & 97.14 & र & 33 & 34 & 94.28 & 97.14 \\
\hline ग & 33 & 35 & 94.28 & 100 & ल & 33 & 35 & 94.28 & 100 \\
\hline घ & 33 & 34 & 94.28 & 97.14 & व & 32 & 33 & 91.42 & 94.28 \\
\hline च & 33 & 34 & 94.28 & 97.14 & श & 32 & 33 & 91.42 & 94.28 \\
\hline छ & 34 & 35 & 97.14 & 100 & ष & 32 & 33 & 91.42 & 94.28 \\
\hline ज & 34 & 34 & 97.14 & 97.14 & स & 32 & 33 & 91.42 & 94.28 \\
\hline झ & 34 & 34 & 97.14 & 97.14 & ह & 32 & 33 & 91.42 & 94.28 \\
\hline ट & 33 & 34 & 94.28 & 97.14 & क्ष & 32 & 33 & 91.42 & 94.28 \\
\hline ठ & 33 & 34 & 94.28 & 97.14 & ज्ञ & 31 & 33 & 88.57 & 94.28 \\
\hline ड & 33 & 34 & 94.28 & 97.14 & त्र & 31 & 32 & 88.57 & 91.42 \\
\hline
\end{tabular}

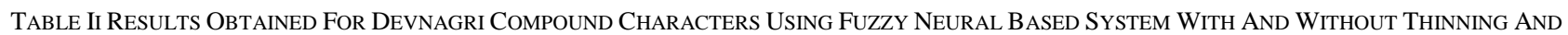
COMPARATIVE RESULTS WITH PREVIOUSLY IMPLEMENTED SYSTEMS

\begin{tabular}{|c|c|c|c|c|c|c|c|c|c|c|}
\hline \multirow{2}{*}{$\begin{array}{c}\text { Input } \\
\text { Character }\end{array}$} & \multicolumn{2}{|c|}{$\begin{array}{c}\text { Recognition } \\
\text { out of } 35 \\
\end{array}$} & \multicolumn{2}{|c|}{ Accuracy } & \multicolumn{3}{|c|}{$\begin{array}{c}\text { Recognition } \\
\text { out of } 35\end{array}$} & \multicolumn{3}{|c|}{ Accuracy } \\
\hline & $\begin{array}{l}\text { Without } \\
\text { Thinning }\end{array}$ & $\begin{array}{c}\text { With } \\
\text { Thinning }\end{array}$ & $\begin{array}{l}\text { Without } \\
\text { Thinning }\end{array}$ & $\begin{array}{c}\text { With } \\
\text { Thinning }\end{array}$ & $\begin{array}{c}\text { Neural } \\
\text { Network } \\
\text { based }\end{array}$ & $\begin{array}{c}\text { Fuzzy } \\
\text { Rule } \\
\text { based }\end{array}$ & $\begin{array}{c}\text { Fuzzy } \\
\text { Neural } \\
\text { based }\end{array}$ & $\begin{array}{c}\text { Neural } \\
\text { Network } \\
\text { based }\end{array}$ & $\begin{array}{c}\text { Fuzzy } \\
\text { rule } \\
\text { based }\end{array}$ & $\begin{array}{c}\text { Fuzzy } \\
\text { Neural } \\
\text { based }\end{array}$ \\
\hline स्व & 30 & 31 & 85.71 & 91.42 & 17 & 30 & 31 & 48.57 & 85.71 & 91.42 \\
\hline त्व & 30 & 31 & 85.71 & 91.42 & 17 & 30 & 31 & 48.57 & 85.71 & 91.42 \\
\hline त्य & 31 & 31 & 91.42 & 91.42 & 19 & 31 & 31 & 54.28 & 91.42 & 91.42 \\
\hline ध्व & 30 & 31 & 85.71 & 91.42 & 19 & 30 & 31 & 54.28 & 85.71 & 91.42 \\
\hline म्ल & 29 & 30 & 82.85 & 85.71 & 17 & 29 & 30 & 48.57 & 82.85 & 85.71 \\
\hline ध्य & 30 & 30 & 85.71 & 85.71 & 19 & 30 & 30 & 54.28 & 85.71 & 85.71 \\
\hline च्य & 30 & 31 & 85.71 & 91.42 & 17 & 30 & 31 & 48.57 & 85.71 & 91.42 \\
\hline क्व & 30 & 31 & 85.71 & 91.42 & 16 & 30 & 31 & 45.71 & 85.71 & 91.42 \\
\hline न्य & 30 & 31 & 85.71 & 91.42 & 19 & 30 & 31 & 54.28 & 85.71 & 91.42 \\
\hline श्व & 30 & 31 & 85.71 & 91.42 & 16 & 30 & 31 & 45.71 & 85.71 & 91.42 \\
\hline
\end{tabular}




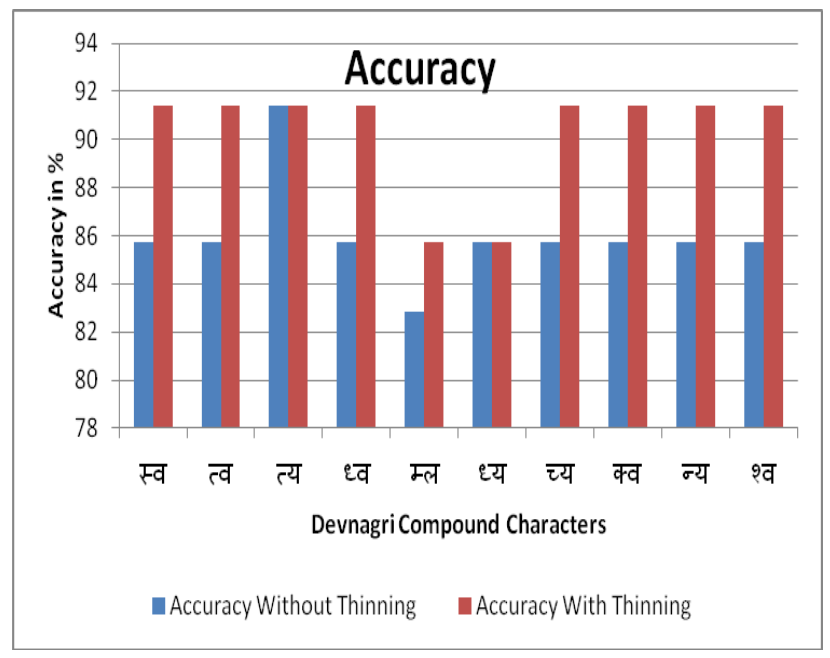

Fig. 2 Accuracy of Fuzzy Neural based System with and without thinning for Compound Characters

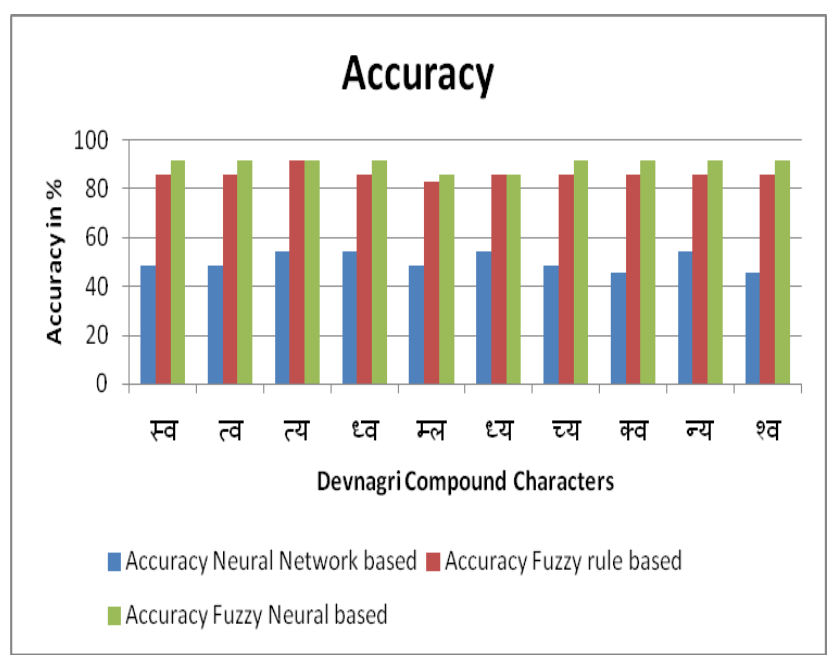

Fig. 3 Accuracy of Fuzzy Neural based System, Fuzzy based System and Neural Network based System for Compound Characters

TABle Iit Comparative Results ObTaINEd For PREviously IMPLEMENTEd Systems AND Proposed System

\begin{tabular}{|c|c|c|c|c|c|c|c|c|c|c|c|c|c|}
\hline \multirow[b]{2}{*}{$\begin{array}{c}\text { Input } \\
\text { Character }\end{array}$} & \multicolumn{3}{|c|}{$\begin{array}{c}\text { Recognition } \\
\text { out of } 35\end{array}$} & \multicolumn{3}{|c|}{ Accuracy } & \multirow[b]{2}{*}{$\begin{array}{c}\text { Input } \\
\text { Character }\end{array}$} & \multicolumn{3}{|c|}{$\begin{array}{c}\text { Recognition } \\
\text { out of } 35\end{array}$} & \multicolumn{3}{|c|}{ Accuracy } \\
\hline & 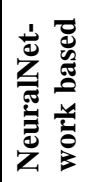 & 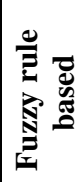 & 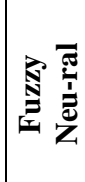 & 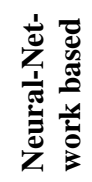 & 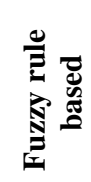 & | & & 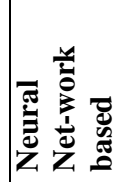 & 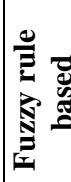 & 践 & 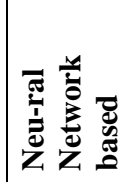 & 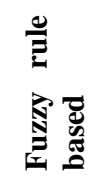 & 总 \\
\hline अ & 31 & 32 & 33 & 88.57 & 91.42 & 94.28 & ढ & 26 & 33 & 33 & 74.28 & 94.28 & 94.28 \\
\hline आ & 33 & 33 & 33 & 94.28 & 94.28 & 94.28 & ण & 31 & 33 & 34 & 88.57 & 94.28 & 97.14 \\
\hline इ & 33 & 33 & 33 & 94.28 & 94.28 & 94.28 & त & 31 & 33 & 34 & 88.57 & 94.28 & 97.14 \\
\hline ई & 33 & 33 & 33 & 94.28 & 94.28 & 94.28 & थ & 28 & 33 & 34 & 80.00 & 94.28 & 97.14 \\
\hline 3 & 31 & 32 & 34 & 88.57 & 91.42 & 97.14 & द & 33 & 33 & 34 & 94.28 & 94.28 & 97.14 \\
\hline ऊ & 31 & 32 & 34 & 88.57 & 91.42 & 97.14 & ध & 29 & 32 & 32 & 82.85 & 91.42 & 91.42 \\
\hline ए & 33 & 33 & 34 & 94.28 & 94.28 & 97.14 & न & 33 & 33 & 33 & 94.28 & 94.28 & 94.28 \\
\hline ऐ & 33 & 33 & 34 & 94.28 & 94.28 & 97.14 & प & 31 & 32 & 33 & 88.57 & 91.42 & 94.28 \\
\hline ओ & 28 & 33 & 34 & 80.00 & 94.28 & 97.14 & फ & 28 & 33 & 34 & 80.00 & 94.28 & 97.14 \\
\hline औ & 28 & 32 & 33 & 80.00 & 91.42 & 94.28 & ब & 28 & 32 & 33 & 80.00 & 91.42 & 94.28 \\
\hline अं & 26 & 32 & 33 & 74.28 & 91.42 & 94.28 & भ & 26 & 32 & 33 & 74.28 & 91.42 & 94.28 \\
\hline अ: & 26 & 33 & 34 & 74.28 & 94.28 & 97.14 & म & 26 & 33 & 33 & 74.28 & 94.28 & 94.28 \\
\hline क & 33 & 33 & 34 & 94.28 & 94.28 & 97.14 & य & 26 & 33 & 34 & 74.28 & 94.28 & 97.14 \\
\hline ख & 31 & 33 & 34 & 88.57 & 94.28 & 97.14 & र & 31 & 33 & 34 & 88.57 & 94.28 & 97.14 \\
\hline ग & 33 & 33 & 35 & 94.28 & 94.28 & 100 & ल & 31 & 33 & 35 & 88.57 & 94.28 & 100 \\
\hline घ & 31 & 33 & 34 & 88.57 & 94.28 & 97.14 & व & 26 & 32 & 33 & 74.28 & 91.42 & 94.28 \\
\hline च & 33 & 33 & 34 & 94.28 & 94.28 & 97.14 & श & 28 & 32 & 33 & 80.00 & 91.42 & 94.28 \\
\hline छ & 31 & 34 & 35 & 88.57 & 97.14 & 100 & ष & 28 & 32 & 33 & 80.00 & 91.42 & 94.28 \\
\hline ज & 31 & 34 & 34 & 88.57 & 97.14 & 97.14 & स & 29 & 32 & 33 & 82.85 & 91.42 & 94.28 \\
\hline झ & 31 & 34 & 34 & 88.57 & 97.14 & 97.14 & ह & 28 & 32 & 33 & 80.00 & 91.42 & 94.28 \\
\hline ट & 31 & 33 & 34 & 88.57 & 94.28 & 97.14 & क्ष & 27 & 32 & 33 & 77.14 & 91.42 & 94.28 \\
\hline б & 28 & 33 & 34 & 80.00 & 94.28 & 97.14 & ज्ञ & 27 & 31 & 33 & 77.14 & 88.57 & 94.28 \\
\hline ड & 31 & 33 & 34 & 94.28 & 94.28 & 97.14 & त्र & 26 & 31 & 32 & 74.28 & 88.57 & 91.42 \\
\hline
\end{tabular}




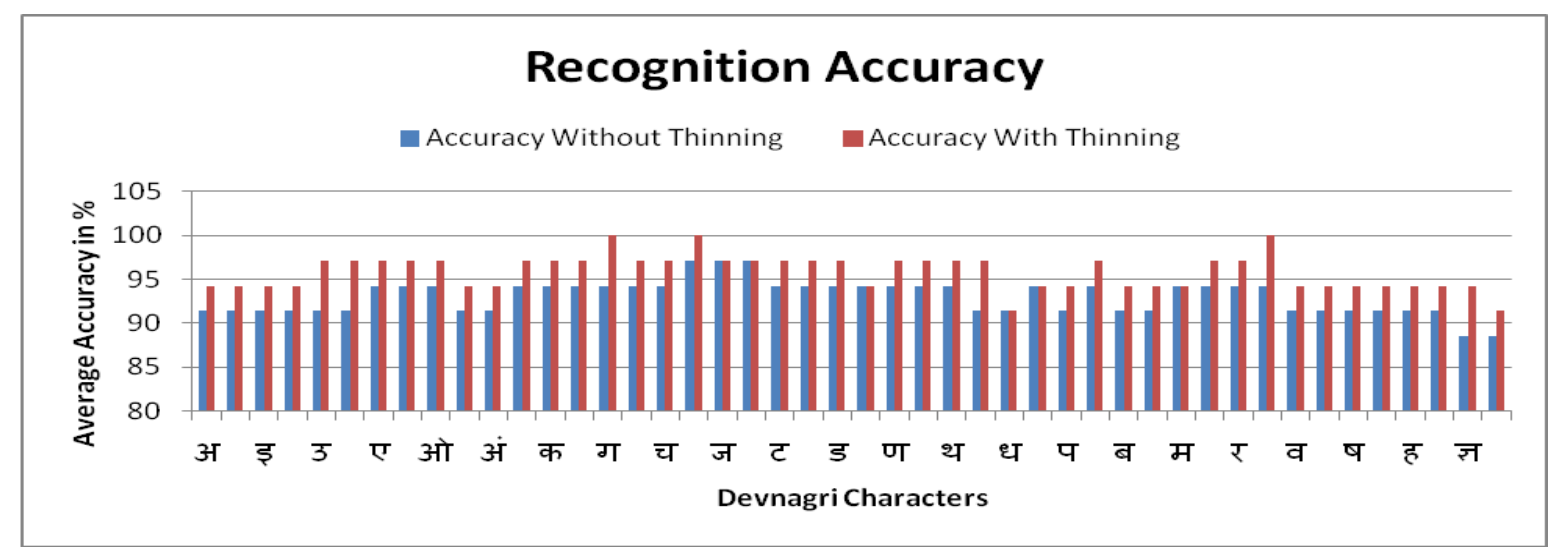

Fig. 4 Accuracy of Fuzzy Neural based System for Devnagri Characters with and without Thinning

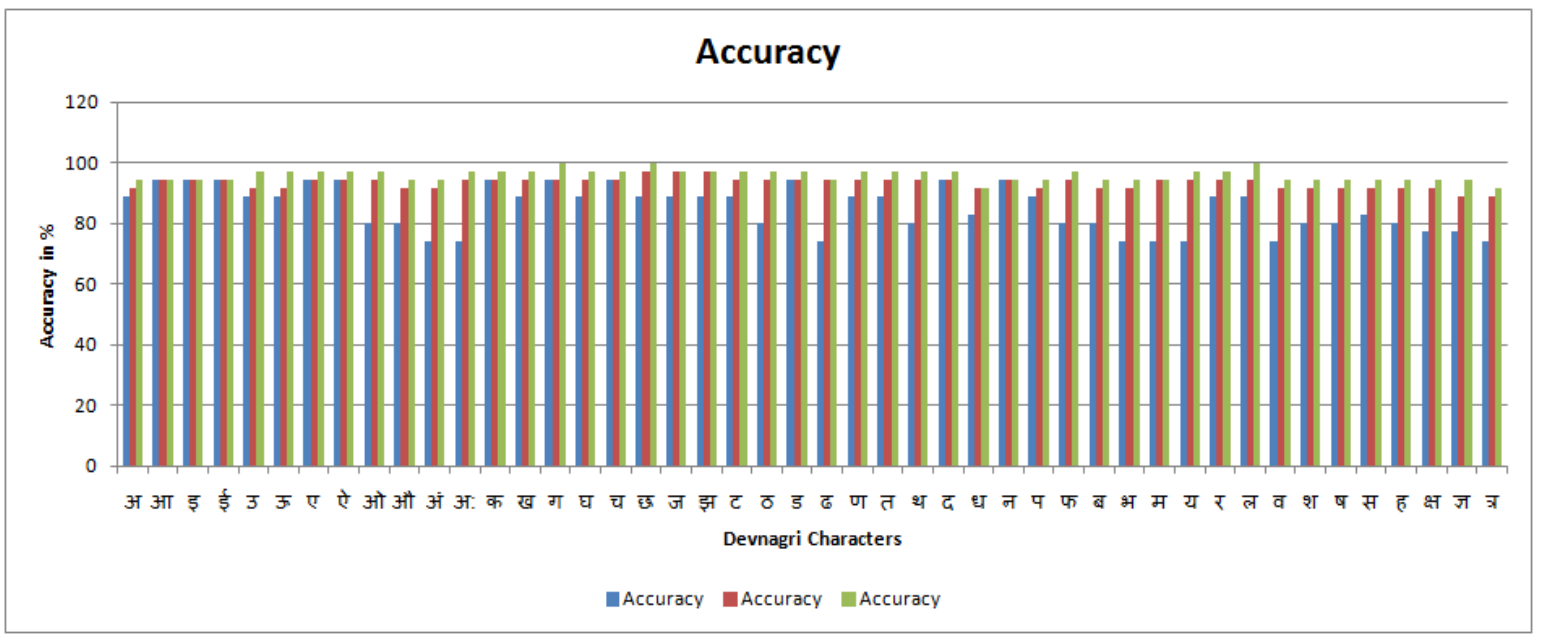

Fig. 5 Accuracy of Fuzzy Neural based System, Fuzzy based System and Neural Network based System for Devnagri Characters

\section{CONCLUSION}

The proposed system based on hybrid approach developed by combination of neural network and fuzzy rules used for optimizing the weights shows improvisation in the recognition accuracy. Further applying the 8 step Rotation in-variant thinning algorithm as a pre-processing activity helps not only in preserving the shape of the characters but also in improving the recognition accuracy substantially from $88.57 \%-97.14 \%$ to $91.42 \%-100.00 \%$. A substantial improvisation in the recognition accuracy can be seen from 45.71- 54.28, 82.85 - 91.42 and $85.71-91.42 \%$ for hand written Devnagri Compound Characters when tested on neural based, fuzzy rule based and fuzzy neural based systems respectively. Average Recognition accuracy for hand written Devnagri characters has gradually increased from 74.28- 94.28, 91.42 - 97.04 and $91.42-100 \%$ for the implemented systems using Neural Network, Fuzzy based, and Fuzzy Neural based approach respectively. We further expect improvements in the recognition accuracy for hybrid approaches like neuro-gene, neural with nature inspired searching algorithms.

\section{REFERENCES}

[1] Choudhary and Rishi, "Improving The Character Recognition Efficiency of Feed Forward BP Neural Network", International Journal of Computer Science \& Information Technology (IJCSIT), Vol. 3, No 1, pp. 85-96, Feb 2011.

[2] Vikas J Dongre and Vijay H Mankar, "Devanagari Document Segmentation Using Histogram Approach", International Journal of Computer Science, Engineering and Information Technology (IJCSEIT), Vol.1, No.3, pp. 46-53, August 2011.

[3] R.M. Noorullah, and Dr. A. Damodaran, "Innovative Thinning and Gradient Algorithm For Edge Field and Categorization Skeleton Analysis of Binary And Grey Tone Images", Journal Of Theoretical And Applied Information Technology, Vol. 5. No.1, pp. 75-80, 2009.

[4] Jon Almazan, Albert Gordo, Alicia Forn_es, and Ernest Valveny, "Word Spotting and Recognition with Embedded Attributes", IEEE Transactions on Pattern Analysis And Machine Intelligence, Vol. 36, No.12, pp. 2552- 2566, December 2014.

[5] P. M. Yawalkar and M. U. Kharat, " Handwritten Character Recognition Systems", International Journal of Advanced Trends in Computer Science and Engineering, Vol. 5, No. 6, pp. 95- 110, NovDec 2016.

[6] Prachi Mukherji, and PritiRege, "Shape Feature and Fuzzy logic based offline Devanagari handwritten optical character Recognition", International Journal of Pattern Recognition Research, Vol. 4, pp. 52-68, 2009.

[7] Maher Ahmed and Rabab Ward, "A Rotation Invariant Rule-Based Thinning Algorithm for Character Recognition", IEEE Transactions on Pattern Analysis And Machine Intelligence, Vol. 24, No. 12, pp.1672-1678, Dec. 2002. 
[8] P. M. Yawalkar, M. U. Kharat and S. V. Gumaste, "Segmentation of Multiple Touching Hand Written Devnagari Compound Characters: Image Segmentation for FeatureExtraction", IGI Global, Chapter 8, pp.140-163, May 2018.

[9] Yu Qiao, Mikihiko Nishiara, and Makoto Yasuhara, "A Framework Toward Restoration of Writing Order from Single-Stroked Handwriting Image", IEEE Transactions On Pattern Analysis And Machine Intelligence, Vol. 28, No. 11, pp. 1724- 1737, Nov. 2006.

[10] H. B. Kekre, M. U. Kharat and S. R. Sange, "Image data compression using new half toning operators and run length encoding", Springer, DOI 10.1007/978-81-8489-989, pp. 208-213, 2011.

[11] Lazzerini, Marcelloni, and Reyneri, "Neuro-fuzzy Off-line Recognition of Handwritten Sentences", in Proceedings of Fourth International Conference on knowledge-Based Intelligent Engineering Systems, Sept 2000, pp. 440-443.

[12] M. Hanmandlu, K. R. Murali Mohan and Sourav Chakraborty, "Fuzzy Logic Based Handwritten Character Recognition", IEEE, pp. 42- 45, 2001

[13] Sara L. Su, Chenyu Wu, and Ying-Qing Xu, "A Hybrid Approach to Rendering Handwritten Characters", in Proceedings of the 12th International Conference in Central Europe on Computer Graphics, Visualization and Computer Vision, pp. 1-8, January 2004.

[14] Alginahi, El-Feghi, Ahmadi and Sid-Ahmed, "Optical Character Recognition System Based On A Novel Fuzzy Descriptive Features", in Proceedings of ICSP-04, pp. 926-929, 2004.

[15] Mohammed Zeki Khedher, and Ghayda Al-Tali, "Recognition of secondary characters in handwritten Arabic using Fuzzy Logic", in Proceedings of International Conference on Machine Intelligence (ICMI'05), 2005.

[16] Yu Qiao, MikihikoNishiara, and Makoto Yasuhara, "A Framework toward Restoration of Writing Order from Single-Stroked Handwriting Image", IEEE Transactions On Pattern Analysis And Machine Intelligence, Vol. 28, No. 11, pp. 1724- 1737, Nov. 2006.

[17] Thierry Artieres, Sanparith Marukatat, and Patrick Gallinari, "Online Handwritten Shape Recognition Using Segmental Hidden Markov Models", IEEE Transactions On Pattern Analysis And Machine Intelligence, Vol. 29, No. 2, pp. 205- 217, Feb. 2007.

[18] Koorosh Samimi Daryoush, Maryam Khademi, Alireza Nikookar, and Aida Farahani, "The Application of Local Linear N euro Fuzzy Model in Recognition of Online Persian Isolated Characters", in Proceedings of International Conference on Advanced Computer Theory and Engineering (ICACTE), pp. 574-577, 2010.

[19] Sushama Shelke, and Shaila Apte, "A Multistage Handwritten Marathi Compound Character Recognition Scheme using Neural Networks and Wavelet Features", International Journal of Signal Processing, Image Processing and Pattern Recognition, Vol. 4, No. 1, pp. 81-94, March 2011.

[20] Ranpreet Kaur, and Baljit Singh, "A Hybrid Neural Approach For Character Recognition System", International Journal of Computer
Science and Information Technologies, Vol. 2, No. 2, pp. 721-726, 2011.

[21] S.F. Bahgat, S. Ghomiemy, S. Aljahdali, and M. Alotaibi, "A Proposed Hybrid Technique for Recognizing Arabic Characters", International Journal of Advanced Research in Artificial Intelligence, Vol. 1, No. 4, pp. 35-43, 2012.

[22] Moncef Charfi, Monji Kherallah, Abdelkarim El Baati, and Adel M. Alimi, "A New Approach for Arabic Handwritten Postal Addresses Recognition”, International Journal of Advanced Computer Science and Applications, Vol. 3, No. 3, pp. 1-7, 2012.

[23] Debananda Padhi, "Novel Hybrid approach for Odia Handwritten Character Recognition System", International Journal of Advanced Research in Computer Science and Software Engineering, Vol. 2, No. 5, pp. 150-157, May 2012.

[24] Satish Lagudu, CH. V. Sarma, "Hand Writing Recognition Using Hybrid Particle Swarm Optimization \& Back Propagation Algorithm", International Journal of Application or Innovation in Engineering, Vol. 2, No. 1, pp. 75-81, Jan. 2013.

[25] K.V. Kale, and M. M. Kazi, "Handwritten and Printed Devanagari Compound using Multiclass SVM Classifier with Orthogonal moment Feature", International Journal of Computer Applications, Vol. 71, No. 24, pp. 21-27, June 2013

[26] Poonam B. Kadam, Latika R. Desai, "A Hybrid Approach to Detect and Recognize Texts in Images", International Journal of Research in Computer and Communication Technology, Vol. 2, No. 7, pp. 405410, July 2013.

[27] Seema A. Dongare, Dhananjay Kshirsagar, and Snehal Waghchaure, "Handwritten Devanagari Character Recognition using Neural Network", IOSR Journal of Computer Engineering, Vol. 16, No. 2, pp. 74-79, Mar-Apr. 2014.

[28] J. R. Prasad, and U. V. Kulkarni, "Gujrati Character Recognition using Adaptive Neuro Fuzzy Classifier", proceedings of International Conference on Electronic Systems, Signal Processing and Computing Technologies, pp. 407-414, 2014.

[29] Saniya Ansari, and Udaysingh Sutar, "Devanagari Handwritten Character Recognition using Hybrid Features Extraction and Feed Forward Neural Network Classifier (FFNN)", International Journal of Computer Applications, Vol. 129, No.7, pp. 22-27, Nov. 2015.

[30] Santosh Kumar Henge, and Dr. B. Rama, "OCR-Mirror Image Reflection Approach Document Back Side Character Recognition by using Neural Fuzzy Hybrid System", in Proceedings of 7th International Advance Computing Conference, IEEE, pp. 738-743, 2017.

[31] Mahesh Jangid, and Sumit Srivastava, "Handwritten Devanagari Character Recognition Using Layer-Wise Training of Deep Convolutional Neural Networks and Adaptive Gradient Methods", Journal of Imaging, Feb. 2018 